\title{
Las voluntades anticipadas en Uruguay: reflexiones sobre la Ley $18473^{*}$ The advance directives in Uruguay: Reflections on the law 18473
}

Ramiro Benítez ${ }^{* *}$

\section{RESUMEN}

El artículo describe el tratamiento que a nivel nacional se le ha dado a las Voluntades Anticipadas. Se parte de una visión que vincula a los Derechos Humanos y jerarquiza la expresión de voluntad de una persona ante una eventual enfermedad incurable. Se analiza el texto legal vigente señalando las principales imprecisiones cometidas tanto por el legislador como por quien tuvo a su cargo la reglamentación, para finalizar con una reflexión sobre cuales serian las reformas que se deberian llevar a cabo para dinamizar y hacer efectiva a esta figura jurídica.

PALABRAS CLAVE: Derechos humanos, consentimiento, forma documental, buen morir.

\section{ABSTRACT}

The article describes the treatment given, at the national level, to Living Wills. It is part of a vision that links Human Rights and respects the expression of free will of a person with an eventually incurable disease. It analyzes the current legal text by indicating the main inaccuracies committed both by the legislator and those in charge of the regulation, concluding with a reflection on what reforms should be brought to each to streamline the law and make this legal structure effective.

KEY WORDS: Human rights, consent, documentary form, dying well.

\footnotetext{
* Recibido: 6 de enero de 2015. Aceptado: 2 de marzo de 2015.

** Profesor de alta dedicación del Área de formación profesional en Notariado en la Universidad Católica del Uruguay. (ramiro.benitez@ucu.edu.uy)
} 


\section{SUMARIO}

1. Palabras preliminares

2. El goce de la vida. La ética y el derecho

3. Diferencia entre voluntades anticipadas y otros conceptos

4. Análisis normativo

5. Capacidad

6. Consentimiento

7. La forma documental

8. Inconvenientes que presenta el instituto de la representación

9. Colofón

\section{Palabras preliminares}

Antes de comenzar con el análisis normativo respecto a lo que el derecho uruguayo ha denominado voluntades anticipadas, es necesario enunciar algunas consideraciones previas que ayudarán a mejor comprender este tema en el contexto nacional y, así, señalar lo que el legislador omitió, equivocó, no consideró o desconocía.

El reconocimiento de los derechos de las personas ha abierto una nueva perspectiva respecto a las garantías, derechos y deberes de las personas, lo cual se ha verificado como un giro importante en relación con los derechos humanos en estos últimos años. Se ha abandonado la mirada de un Estado asistencialista hacia un modelo basado en lo social. Esto ha permitido una nueva lectura para el reconocimiento de este tipo de derechos, y la puesta en marcha de mecanismos para su dinamización, transparencia y efectivo ejercicio.

Cuando entran en juego los derechos fundamentales de los ciudadanos, se deben tener en cuenta dos factores fundamentales para su viabilidad, la seguridad del destinatario y la consideración de quien legisla:

- Los valores en los cuales se basan los derechos deben contar con un grado de aceptación social que trascienda la esfera judicial.

- Se deben manejar con cierto rigor jurídico-científico por parte del Poder Judicial que permita su incorporación. 
La Constitución Nacional ${ }^{1}$ dispone que los tratados internacionales deberán ser ratificados por el Parlamento Nacional, para que sean norma vigente en el ordenamiento jurídico nacional, por medio de la promulgación de una ley.

En relación con los derechos humanos, la Carta Magna hace un reconocimiento amplio, como lo dispone su artículo 72: "La enumeración de derechos, deberes y garantías hecha por la Constitución no excluye los otros que son inherentes a la personalidad humana o se derivan de la forma republicana de gobierno". Esto es completado con el artículo 332:

Los preceptos de la presente Constitución que reconocen derechos a los individuos, así como los que atribuyen facultades e imponen deberes a las autoridades públicas, no dejarán de aplicarse por falta de la reglamentación respectiva, sino que ésta será suplida, recurriendo a los fundamentos de leyes análogas, a los principios generales de derecho y a las doctrinas generalmente admitidas.

Lo cual sería suficiente para que proceda la incorporación de determinados derechos no manifestados expresamente, o sea, desde una visión del derecho objetivo (Constitución) como fundamento del derecho subjetivo. Si bien no están textualmente todos los derechos, adquieren visibilidad desde el momento en que el ciudadano los ejerce. Se puede decir, entonces, que se promueve una concepción individualista del derecho. Los reclamos, deben ser fuente jurídica primaria.

Este tipo de norma ha contribuido a la aparición de la figura del bloque de constitucionalidad ${ }^{2}$ aplicado a derechos fundamentales, como manera de obtener la fluidez necesaria del derecho al momento del reclamo. Destaca la efectividad en su ejercicio.

Decía Charles De Gaulle que "Una constitución es un espíritu, las instituciones una práctica”. ${ }^{3}$ El espíritu de la Constitución debe pasar por un contenido estrictamente social, sobrevolar todo el ordenamiento. El intérprete debe lograr, mediante la lectura de su articulado, rescatarlo para su efectiva aplicación.

\footnotetext{
${ }^{1}$ Constitución Nacional, 1996.

${ }^{2}$ Risso Ferrand, citando a Nogueira, observa que "en América Latina hay una poderosa corriente cada vez más generalizada que reconoce un bloque de derechos integrado por los derechos asegurados explícitamente en el texto constitucional, los derechos contenidos en los instrumentos internacionales de derechos humanos y los derechos implícitos, donde el operador jurídico debe interpretar los derechos buscando preferir aquella fuente que mejor protege y garantiza los derechos de la persona humana", Risso FerRand, Martin. Derecho Constitucional, 2006, p. 114). ${ }^{3}$ De Gaulle, Charles. Conférence de presse depuis qu'il est à la tête de la Cinquième République. 31 de enero, 1964.
} 


\section{El goce de la vida. La ética y el derecho}

Ya centrándonos en el derecho a la vida, el artículo 7 de la Constitución establece: "Los habitantes de la República tienen derecho a ser protegidos en el goce de su vida [...] Nadie puede ser privado de estos derechos sino conforme a las leyes que se establecen por razones de interés general".

Frente a esta norma, cabe la siguiente pregunta: ¿Qué se entiende como "el goce" de la vida? Si se establece en el orden constitucional la calidad de goce de vida, esta condición responderá a un orden muy personal del individuo. Pasa al ámbito de la valoración personal, dependiendo sólo de una apreciación íntima y subjetiva.

Definir "gozar de la vida", en una interpretación primaria y simplista, sería lo mismo que ser libre de ejercer sus derechos con el sólo límite de la norma de orden público, dictada en custodia de un bien superior, general y común para el resto de los ciudadanos.

Muchas veces se ha usado la expresión: "mi derecho termina donde comienza el derecho del otro", frase que no es del todo acertada. A veces los derechos de los individuos circulan por carriles paralelos. Quizás lo correcto sería decir que "mi derecho termina cuando con mi actuar podría vulnerar el derecho de otros".

Hay que tener presente que la vida de todo individuo se compone de su parte física y espiritual. Gozar de la vida tiene relación con ambos: poder vivir físicamente sano y activo, sustentado por un espíritu que le permita desarrollarse dignamente. Esto responde a la propia condición y elección de la persona como ser individual y autónomo. Éste será el punto de arranque como el presupuesto lógico, donde las premisas permitan concluir con argumentos certeros y sólidos, enmarcados en el derecho, para concluir en la concepción de goce.

El Estado debe brindar las mayores garantías y ser solidario para que sus ciudadanos desarrollen las potencialidades que le permitan, a su vez, el avance de otros. 0 sea, este reconocimiento implica el principio de todos aquellos derechos fundamentales que se vinculan con el respeto, la aceptación y la tolerancia. Tendrá derecho a ser feliz, a tener un nombre, a pertenecer a una familia, a educarse, a estudiar, a profesar la religión que quiera, o ninguna, a tener las mismas oportunidades que otros, a prepararse, a trabajar, a tener una familia; en defınitiva, a poder vivir conforme su propia convicción dentro de una concepción humanista.

El objetivo de las directivas anticipadas es evitar la dilación de la vida cuando no existen posibilidades concretas de revertir la situación ante un 
diagnóstico médico. 0 sea, cuando esa persona ya no puede gozar de su vida porque el seguir viviendo significa un tormento para sí y para su entorno. Estos son los casos en que deben actuar este tipo de estipulaciones. Penoso es ver cómo un ser querido ya sin ganas, fuerzas, conciencia, ni ninguna posibilidad, permanece en una situación invariable y lo único que se espera es que obtenga descanso y paz.

¿Por qué una persona, en uso de sus facultades y en completa conciencia, no puede prever cuál es el procedimiento que, llegado el momento de un diagnóstico irreversible, le sea aplicado? ¿Por qué no se puede establecer en un acto de amor generoso evitar a su familia una espera que producirá un final anunciado?

Previo a la fundamentación jurídica, se hace necesario mencionar la perspectiva social actual. En los últimos años se ha tendido mucho a la reivindicación de la libertad del hombre en un sentido material o corpóreo, como apelando al ámbito de la conciencia y los valores, por lo tanto, al plano de la ética.

$\mathrm{Al}$ hombre se le considera un ser libre para determinar su propia moral, su propia conducta, responder al orden de sus propios principios. Se acerca a la libertad moral individualista que requiere un continuo ejercicio de la tolerancia y aceptación del otro, lo cual podría definirse como un consenso de la diversidad, donde se dejan fuera los aspectos formales de la búsqueda de la verdad y del bien por ser éstos patrimonio exclusivo e individual del hombre.

Se sitúa en una esfera diferente del poder político, pues no se podrá legislar sobre la conciencia de los individuos y no se podrá forzarlos a suscribir normas morales. De otra manera, se estaría violentando el ejercicio de las libertades individuales y atacando la dignidad de las personas.

De esa combinación de ética y derecho, con referencia a las directivas anticipadas, es oportuno destacar algunas premisas contemporáneas:

- La imposición del concepto "calidad de vida" frente al de "vida como bien santo".

- La intimidad del hombre como el ejercicio autónomo de actos y toma de decisiones propias.

- La declaración de voluntad individual debe ser tomada en cuenta en cada instancia, pues su falta de observancia acarrearía una violación a los derechos fundamentales de la persona.

- La dignidad pasa por una apreciación personal, individual y depende enteramente de lo que el involucrado entienda por tal. Sólo él puede decidir lo que mejor considere dentro de su esfera personal. 
Contrariamente a lo dicho, cabría preguntarse también: ¿Qué sucede cuando ese ciudadano ya no puede gozar su vida? Ciertamente, es muy difícil tener respuestas acordes con la dimensión que asumiría su argumentación.

Uno nace para ser feliz, no para sufrir, y el morir es la certeza de lo finito del ser humano. Ambos acontecimientos deben ser aceptados como procesos naturales que deben ser vividos de manera digna.

Uno tiene derecho a un buen vivir y debería tener derecho a un buen morir de acuerdo con sus convicciones más íntimas, las cuales un extraño podrá inferir pero nunca tener certidumbre. Por lo tanto, en cuanto a conceptos tan subjetivos como el buen vivir o el buen morir, se debe estar atento al sentimiento de la persona hacia el hecho de la propia vida.

Mas allá de los componentes cognoscitivos, afectivos o conductuales del individuo, cada uno tiene su propia representación de cómo cumplir con la premisa de tener un buen vivir. Sin embargo, el tema de la muerte, desde un punto de vista cultural, es bastante ajeno al pensamiento racional del individuo y del sentir colectivo.

Desde su concepción antropológica, el tema de la muerte es un tema vedado, sobre el cual no se habla, como si por evitar nombrarlo desapareciera o no existiera. Se elude por asociarse al sufrimiento. Más allá de esto, cuando lo fáctico se anuncia o sucede, en la propia intimidad del ser humano surgen cuestiones asociadas a la negación del dolor. Se le da una categoría de valor para la propia vida, lo cual se traduce en una frase: no soportar padecimientos.

De esta breve explicación surge la propuesta de llamar a ese momento "buen morir", con la intencionalidad de prever que ante lo irremediable de esa situación, y de acuerdo con sus propias convicciones y creencias, se quiere que ese momento trascurra en paz y sin sufrimiento, conforme a decisiones personales y, por lo tanto, legítimas por la calidad del emisor.

Los cambios científicos y tecnológicos han contribuido a una revisión permanente de los conceptos vida y muerte desde un pluralismo de carácter ético, filosófico, religioso y cultural no puramente clínico, sino vinculadas a las concepciones de la existencia. 0 sea, desde lo que la persona ha visto, ha aprendido y ha vivido, en definitiva, de su propio mundo.

De ahí que el principio de autodeterminación individual ha sido incorporado y reconocido por los Estados democráticos como el derecho al desarrollo de la personalidad propia.

El artículo 44 de la Constitución establece:

El Estado legislará en todas las cuestiones relacionadas con la salud e higiene públicas, procurando el perfeccionamiento físico, moral y 
social de todos los habitantes del país. Todos los habitantes tienen el deber de cuidar su salud, así como de asistirse en caso de enfermedad. El Estado proporcionará gratuitamente los medios de prevención y de asistencia tan sólo a los indigentes y carentes de recursos suficientes.

Este artículo impone el deber a la persona de prestar atención a su salud, no sólo por la protección propia sino de la comunidad.

¿Qué sucede cuando ese deber no es ejercido? ¿Qué consecuencias tiene? ¿Podrá el Estado imponer a la persona coactivamente la asistencia obligatoria? Sin lugar a dudas, la respuesta a esta última pregunta es afirmativa siempre y cuando se ponga en peligro al resto de la comunidad (casos de pandemia, enfermedades contagiosas).

Muy distinto será el caso donde la enfermedad no involucre un peligro social, sino un padecimiento individual que no afecte a los demás ciudadanos.

¿Cómo lograr que el consentimiento del paciente sea suficientemente efectivo para que el cuerpo médico no ejerza sobre él una especie de paternalismo o ensañamiento terapéutico?

Decidida una persona a establecer su voluntad de manera anticipada, debe contar con un buen asesoramiento profesional que le brinde no sólo certezas sino que despeje sus dudas sobre situaciones reales y objetivadas en el tiempo, sobre lo que puede pasarle y cuáles serán las consecuencias si se procede de tal o cual forma.

Jurídicamente, el consentimiento tiene que ser emitido libremente. De mediar algún tipo de violencia o coacción, éste estaría viciado y, como tal, no tendría valor.

Pero vamos por más: ¿Cómo actuar cuando una persona, desde un estado de bienestar físico y espiritual, decide anticipadamente establecer determinados comportamientos clínicos para cuando se configuren los supuestos por él establecidos?

Esta pregunta, desde un punto de vista objetivo, coloca a la persona ante la suposición de un hecho incierto sobre el cual decide, en su libre albedrío, las pautas para que, llegado un momento particular de su vida, el cuerpo médico proceda de acuerdo con lo que dejó indicado.

La duda que se presenta es si una persona es libre de decidir consciente y de manera responsable ante una noticia que le provoque un estado de conmoción que altere sus emociones, violente su espíritu e incida en sus decisiones de manera no reflexiva.

El miedo a sufrir, el miedo a que sufra su familia o sus seres queridos, la toma de conciencia de lo irreversible de una situación, la supresión de todo 
tratamiento clínico que prolongue artificialmente la vida, o la salvaguarda de la responsabilidad médica, son cuestiones que deben tomarse en cuenta.

Muchas veces, desde el punto de vista clínico, estas directivas anticipadas tensionan al profesional médico por una razón legítima: el objetivo de su carrera es salvar vidas. Muchas veces se ven limitados en el ahora por cuestiones resueltas en el pasado que pueden producir dudas fundadas en su pertinencia. Muchas veces, los datos recabados pueden dirigirse a la reconstrucción de la voluntad del paciente. Pero aquí es donde entran en juego conceptos como el riesgo médico y su gestión. Se ha estudiado mucho sobre estos temas, pero su tratamiento excedería el presente trabajo.

Por otro lado, las directivas concretas y definidas responden a una posición que el individuo tomó y no alteró, vinculadas a su intimidad y, como tal, debe ser respetada. No se puede subestimar al otorgante de una directiva, pensando por él o reconstruyendo su voluntad. De esa manera se violentaría la dignidad de la persona y el médico debería ser pasible de responsabilidad, cosa que no ocurriría en caso de cumplir con el mandato de su paciente.

Cabría plantear que es legítimo legislar sobre cómo vivir así como legislar sobre cómo morir. Esto es una consecuencia de haber nacido y como tal integra el concepto de vida porque toda vida conlleva en sí la potencialidad de la muerte. Nadie vive eternamente. El final de la vida es algo previsible en algunos casos; en otros, no.

\section{Diferencia entre voluntades anticipadas y otros conceptos}

Todo lo vinculado con el tema de la muerte, en relación con las voluntades anticipadas, suele ser tratado de manera confusa, generalmente por su desconocimiento o por convicciones religiosas o filosóficas foráneas, y así se cometen errores desde una perspectiva basada en conceptos incorrectos. ${ }^{4}$

Por eso, es oportuno realizar una serie de precisiones sobre los términos que pueden ser utilizados de manera equivocada y confundir al lector.

A continuación se enunciarán algunos de esos conceptos:

- Muerte digna u ortotanasia. Desde el punto de vista clínico, se le define como aquel procedimiento médico que cuenta tanto con proporcionar alivios médicos necesarios, así como el consuelo y el acompañamiento, tanto al paciente, como al entorno familiar.

\footnotetext{
${ }^{4}$ Gómez-Sancho, R. Altisent, J. Bátiz, L. Ciprés, P. Corral, J.L. González-Fernández, J.A. Herranz, J. Rocafort y J.J. RodriguezSendin. Revista de la Sociedad Española del Dolor, No. 3, vol. 17, Narón, La Coruña, 2010.
} 
- Eutanasia. Etimológicamente significa buena muerte, pero en verdad son decisiones médicas que por la acción o la omisión producen directa o intencionalmente la muerte del paciente, con el fin de terminar con su sufrimiento físico. Se puede dividir en dos tipos:

Directa. Procede cuando se quiere adelantar el proceso de una persona con una enfermedad incurable, mediante el uso de fármacos letales (activa) o cuando se suspende todo tipo de tratamiento médico (pasiva). Indirecta. Se puede definir como el intento de paliar el dolor y sufrimiento; la consecuencia final es producir la muerte del paciente, aun sin buscar ese desenlace de manera directa.

- Suicidio asistido. La diferencia fundamental con el concepto anteriormente analizado es que aquí el sujeto decide poner fin a su vida y solicita que se le proporcionen los elementos necesarios para llevar adelante su cometido. Se diferencia del suicidio porque no se procede con medios violentos, sino con asistencia, de manera cierta y sin dolor.

- Testamento vital. Se identifica con las voluntades anticipadas. Una persona plasma en un documento su voluntad sobre las atenciones médicas que desea recibir en caso de padecer una enfermedad irreversible, incurable o terminal que le lleve al impedimento de expresare por sí misma. Se asocia a este tipo de documento otra serie de estipulaciones en anticipación a una posible incapacitación. Tiene que ver con la parte patrimonial o familiar del declarante.

- Cuidados paliativos. La Organización Mundial de la Salud (oms) los define como el conjunto coordinado de intervenciones sanitarias dirigidas, desde un enfoque integral, a mejorar la calidad de vida de los pacientes y sus familias. Se trata de medidas de prevención y alivio del sufrimiento por medio de la identificación temprana y el tratamiento del dolor y otros problemas físicos, psicosociales y espirituales. Se realizan tanto en el hogar como en el hospital. Son cuidados activos para cuando la enfermedad no responde al tratamiento. Tienen prioridad el control del dolor, de otros síntomas y problemas de orden psicológico, social y espiritual.

Nuestros esfuerzos por ampliar los cuidados paliativos han de centrarse en aliviar el sufrimiento de las personas con menos recursos y hacer posible que estas se beneficien de la asistencia paliativa, ha añadido David Praill, copresidente de wPCA. Se necesitarán valentía y creatividad en el proceso de aprendizaje colectivo sobre cómo integrar los cuidados paliativos en los sistemas de atención de salud con muy pocos recursos. 
De todos estos conceptos, el que se destierra por su propia esencia es el referido a la eutanasia en cualquiera de sus dos sentidos, ya que la muerte sólo puede responder a cuestiones propias de la naturaleza humana y no a la decisión de uno sobre otro.

\section{Análisis normativo}

La ley $18473^{5}$ postergó su entrada en vigencia hasta la aprobación por parte del Poder Ejecutivo del Decreto reglamentario del 4 de diciembre de 2013.

El tiempo transcurrido entre una y otra instancia no fue producto de un espíritu crítico y reflexivo sobre temas tan sensibles. El tiempo no actuó como factor de mejora del texto legal. Basta sólo leer su articulado para comprobar que no hace otra cosa más que ahondar en los errores ya cometidos, agravando en algunos casos su puesta en instrumentación.

La voluntad legislativa quedó acotada tan sólo a una parte de la situación que se pretende solucionar, prescindiendo de otras cuestiones jurídicas que se encuentran involucradas. Quizás por ignorancia o por temor no se intentó disponer sobre ellas.

El tratamiento que ofrece la ley es muy pobre, mal resuelto y deja una serie de circunstancias indeterminadas sin contemplar. Su lectura no pasa por una teoría especial de aplicación sobre la interpretación de la ley, sino por una pésima técnica legislativa, un desconocimiento sobre la legislación y pérdida de fluidez en el derecho.

Si realizamos una breve comparación normativa con otras legislaciones, podremos observar que el tema ha sido mucho más inclusivo, contempla determinadas circunstancias y asume el desafío de cambiar instituciones que han quedado anquilosadas en el tiempo.

Temas como la longevidad, el crecimiento en la expectativa de vida, el reconocimiento de los derechos humanos sociales, culturales y económicos, y los avances científicos han provocado cambios en el tipo de propuestas.

El legislador uruguayo, tímidamente, hizo un intento que se puede calificar de insuficiente. No se ha recapacitado lo suficiente ni se ha tenido la audacia de proponer debates; no lo ha creído necesario para comprender que el derecho debe acompañar los cambios sociales en atención a sus ciudadanos.

Se ha legislado de manera ingrata, sin ahondar en un entendimiento de la realidad. Se ha perdido una buena oportunidad para asumir una discusión madura, que trascendiera lo meramente médico o asistencial y permitiera, en

\footnotetext{
${ }^{5}$ Publicada en el Diario Oficial el 21 de abril de 2009.
} 
primer lugar, trascender el tema; en segundo, reflexionar en la búsqueda de soluciones viables, y por último, lograr plasmarlo en una norma.

Este tipo de asuntos se deben enmarcar en contextos que permitan una apreciación transversal. La ausencia de esto se percibe en la lectura de toda la norma.

En el análisis legislativo, se propone enfocarlo en tres aspectos: la capacidad relacionada con la expresión del consentimiento, la forma documental y la figura del representante impuesta por la ley.

\section{Capacidad}

Desde su comienzo, el texto crea confusión:

Art. $1^{\circ}$.- Toda persona mayor de edad y psíquicamente apta, en forma voluntaria, consciente y libre, tiene derecho a oponerse a la aplicación de tratamientos y procedimientos médicos salvo que con ello afecte o pueda afectar la salud de terceros.

Del mismo modo, tiene derecho de expresar anticipadamente su voluntad en el sentido de oponerse a la futura aplicación de tratamientos y procedimientos médicos que prolonguen su vida en detrimento de la calidad de la misma, si se encontrare enferma de una patología terminal, incurable e irreversible.

Tal manifestación de voluntad, tendrá plena eficacia aun cuando la persona se encuentre luego en estado de incapacidad legal o natural. No se entenderá que la manifestación anticipada de voluntad implica una oposición a recibir los cuidados paliativos que correspondieren. De igual forma podrá manifestar su voluntad anticipada en contrario a lo establecido en el inciso segundo de este artículo, con lo que no será de aplicación en estos casos lo dispuesto en el artículo $7^{\circ}$ de la presente ley.

De su lectura se desprenden algunos conceptos cuestionables:

"Psíquicamente apta". Uno de los puntos que más preocupa es precisar el alcance de la expresión de la voluntad ante una disposición anticipada.

Si el individuo es plenamente capaz, cuenta con información suficiente a su real saber y entender, comprende los alcances de cada punto que le fue explicado ante profesionales de su confianza, los cuales le permitieron contar con todos los elementos que estime pertinentes para expresar conscientemente su voluntad, esa manifestación es admisible. La manifestación de esa voluntad es libre y deliberada. 
¿Quién debe calificar si se encuentra "psíquicamente apto”?, ¿el médico tratante ante quien se realiza la manifestación? Si es ante escribano, ¿éste debe contar con el aval médico? ¿Quién debe juzgar la capacidad de discernimiento del declarante?

Son preguntas sin respuesta. 0 más bien, las respuestas son obvias y por lo tanto innecesarias. Hubiera sido suficiente con enunciar "toda persona plenamente capaz”, refiriéndose a aquel ser que es libre de ejercer el derecho de decidir.

El Decreto reglamentario lo señala de manera similar a lo expresado, pero brinda cierta claridad. Parte de un dato objetivo: si la persona tiene 18 años (mayor de edad), no deberá probar su aptitud psíquica, "excepto que el receptor de esa voluntad tenga duda razonable al respecto”. Sin embargo, no establece parámetros para evaluar esa duda razonable.

En el literal siguiente, al determinar la causa, se delimitó que se trate de una patología terminal, incurable e irreversible. Una de las principales vacilaciones que aparecen en este artículo es que dada su redacción, literalmente lleva a una ambigüedad al momento de dictar la disposición.

El segundo literal del artículo 1 establece un juego de palabras muy contradictorio. Sin duda, la primera parte del artículo refiere al momento de la aplicación del tratamiento; el segundo, a la etapa inmediatamente posterior al diagnóstico.

"Del mismo modo, tiene derecho de expresar anticipadamente su voluntad [...] si se encontrare enferma de una patología terminal, incurable e irreversible.” Al respecto, se pueden brindar dos lecturas:

- Algunos intérpretes sostienen que esa manifestación puede formularse en todo momento, no necesariamente cuando se tiene diagnóstico médico. Se puede anticipar en la incertidumbre se esté o no enfermo. ${ }^{6}$

- Otros, entre los cuales se encuentra el autor del presente, entienden que ante la vaguedad en la expresión "anticipadamente" cabría la posibilidad de que se interprete que corresponde cuando exista un diagnostico confirmado sobre una patología terminal, incurable e irreversible.

Algunos de los argumentos que llevan a sostener esta posición se fundan en el avance de la ciencia, el cual permite que las enfermedades sean consideradas de otra forma con respecto al pasado. La expectativa de vida ha crecido

\footnotetext{
${ }^{6}$ Hormalzteguy, Gabriela. Directivas anticipadas: disposiciones en previsión de la propia incapacidad, Asociación de Escribanos del Uruguay, Montevideo, 2012.
} 
enormemente en los últimos años, producto del progreso científico. Desde el momento de la aprobación de la ley, hasta el día de hoy, ha tenido avances suficientes como para diagnosticar enfermedades anticipadamente, ofrecer tratamientos más eficaces y mayor margen en la expectativa de sobrevivir a determinadas patologías.

\section{Consentimiento}

El dictado de estas directivas entra en la esfera privada de las personas bajo lo que la ciencia jurídica ha denominado el campo de la autonomía de la voluntad.

Es prudente y oportuno señalar el momento en que se emite esa manifestación de voluntad.

En ocasiones opera después de un largo proceso; en otras, sucede de un momento a otro. Pero, si la persona en uso de plenas facultades estipula previamente las condiciones en las cuales no quiere seguir viviendo por considerarlas lesivas a su integridad, no existe otro camino que el respeto a esa decisión. Salvo que, en uso de plena conciencia, quiera manifestar lo contrario y revoque la primera.

También hay que analizar el contexto en que se emite esa voluntad, como la recepción del diagnóstico, el estado del espíritu de la persona en el momento de la noticia, o de la manifestación libre de voluntad y, sobre todo, la apreciación de las consecuencias desde la perspectiva de un informe objetivo por parte del profesional de la salud. Es decir, un buen asesoramiento, acompañado no sólo por información adecuada, sino por "aconsejamiento", como lo destacaba Hugo Pérez Montero ${ }^{7}$ cuando hablaba de la nueva visión del asesoramiento notarial. Destacó que la confianza se vuelve indispensable a la hora de decidir.

Por lo tanto, antes de la instrumentación documental, se debe tener presente, conforme a lo expresado, cómo será ese consentimiento informado (o información consentida) que luego quedará de manifiesto en el documento, el cual deberá cumplir con lo siguiente: ${ }^{8}$

- Capacidad. Tal como se analiza más adelante.

- Voluntariedad. Es un acto de decisión individual y solitario, no debe

\footnotetext{
7 pérez montero, Hugo. "50 años de ejercicio y más", en El notario del siglo xxl, No. 15, 2007, p. 52.

${ }^{8}$ Islas-Saucillo, Margarita. y Muñoz, Cuevas Heberto. "El consentimiento informado. Aspectos bioéticos", en Revista médica del Hospital General de México, №. 63, año Iv, 2010, pp. 267-273.
} 
encontrarse viciado o sospechado de dominación, manipulación ni sugestión.

- Información. Las alternativas que se ofrezcan ante la patología deben ser entendibles, señalar los beneficios y riesgos potenciales o eventuales y las consecuencias de su aplicación.

- Comprensión. El informante debe tener convicción de que el mensaje ha llegado en la dimensión correcta.

Si una persona en uso de sus plenas facultades, en un estado emocional que responde a su estándar de vida y dentro de los parámetros de su desarrollo habitual, decide por sí mismo, sin necesidad de mediar ninguna circunstancia que lo dirija en esa elección, o sea, donde prime su libre albedrío, cuenta con un asesoramiento por él mismo calificado como suficiente, habiendo realizado las consultas del caso a los profesionales de su confianza, decide otorgar directivas anticipadas sobre su salud, no debería ser objetada.

Diferente es la situación en que la persona se encuentra frente a un imprevisto respecto a su salud, sin tiempo que le permita una reflexión profunda fundada en una consulta acorde. Donde su estado emocional gana sobre el estado racional, es capaz de recibir información, pero su discernimiento se confunde y no le permite razonar claramente, por más información que se le brinde.

Las situaciones planteadas son muy diferentes y, como tales, deben contar con un tratamiento especial. El debate permitiría una comprensión, no sólo jurídica, sino interdisciplinaria, ya que es una situación que transversalmente involucra a varias ciencias.

Desde el propio ejercicio profesional, muchas veces se solicita el informe del galeno tratante que evalúe desde el punto de vista médico, el estado emocional en que se encuentre, donde con base en elementos cognitivos, permitan llegar a emitir un juicio válido sobre la declaración emitida.

\section{La forma documental}

Artículo $2^{\circ}$. La expresión anticipada de la voluntad a que refiere el artículo anterior se realizará por escrito con la firma del titular y dos testigos. En caso de no poder firmar el titular, se hará por firma a ruego por parte de uno de los dos testigos.

También podrá manifestarse ante escribano público documentándose en escritura pública o acta notarial. Cualquiera de las formas en que se consagre deberá ser incorporada a la historia clínica del paciente. 
Mucho se ha discutido entre el cuerpo médico sobre la necesidad de que la voluntad quede plasmada por escrito e incorporada a la historia clínica. Se ha cuestionado si corresponde que esa voluntad se materialice en un documento público otorgado ante escribano.

Se ha sostenido que la forma documental y la suscripción del paciente no constituyen un criterio de validez, sino una prueba de aceptación del acto médico propuesto.

Se disiente con lo expresado por los siguientes fundamentos, en consideración de lo expresado por Rodríguez Adrados: ${ }^{9}$

- La forma escrita y la firma del paciente no constituyen tan sólo una prueba, sino la validez de esa información, contrariamente a lo que sostiene el cuerpo médico. Lo trascendente no pasa por lo corpóreo, sino por lo que representa en los hechos esa documentación de voluntad, esa representación que perdura gracias a elementos que permiten su reproducción, con el valor añadido de la firma como confirmación del consentimiento brindado.

- Lo oral es efímero; lo escrito y documentado es perpetuo.

- Estas cuestiones sensibles necesitan de cierta humanización y, sobre todo, tiempo del profesional para el asesoramiento y la información. $\mathrm{Su}$ documentación actúa como resguardo frente a la fragilidad de la memoria.

- La forma documental actúa como un doble aval: por un lado, de que se brindó y se recibió la información adecuada, se comprendió lo que se le trasmitió y, por lo tanto, se consintió libremente. Por otro lado, para la parte médica, que ha cumplido con todos los deberes inherentes a su función. Esa entrevista médica no se puede enmarcar en forma de consulta porque responde a otras cuestiones más íntimas. ${ }^{10}$

El artículo 3 establece una inhibición con respecto al cuerpo médico y al personal asociado con él o con la institución médica. Se pretende preservar la imparcialidad, rechazando que el médico tratante, sus colaboradores, o funcionarios del centro hospitalario, puedan actuar como testigos. Se extiende la inhibición por vía reglamentaria "a los propietarios, accionistas, directores técnicos y administrativos y empleados a cualquier título de hogares, residencias o instituciones”. Por otro lado, no establece dónde se podrán formular

\footnotetext{
${ }^{9}$ Rodriguez Adrados, Antonio. "El principio de la eficacia formal", en Revista notario siglo xxl, No. 48, abril de 2013.

${ }^{10}$ Carminio Castagno, José Carlos. "Algunas disquisiciones sobre la forma jurídica", en Revista del Notariado, No. 100, 1997.
} 
este tipo de declaraciones, lo hace de manera muy genérica e imprecisa por vía reglamentaria: "en las oficinas de Atención al Usuario de las Instituciones prestadoras de servicios de salud, así como también en las del Ministerio de Salud Pública”.

Por lo tanto, se deduce, en concordancia con la inhibición y el lugar donde el paciente debe formular la declaración, que ésta deberá realizarse en otra institución médica, diferente a la que le presta asistencia. No podría realizar esta declaración, por ejemplo, en la misma institución donde está internado. Sin embargo, queda la salvaguarda del notario, quien puede concurrir libremente.

Del mismo modo, se establece que la persona no puede firmar, en el supuesto del documento privado. Lo hará un testigo a su ruego, tal cual lo señala el Código Civil en su artículo 1585. ${ }^{11}$

Con respecto a la revocación, se deja una puerta muy abierta al permitir que se realice de manera verbal por el paciente ante el médico tratante, sin mención a su constancia en la historia clínica, la cual, se supone, debería estar incluida. Se plantea un absurdo. Se reglamenta (más allá de los errores del legislador) el otorgamiento de la voluntad anticipada, con una serie de requisitos que chocan entre sí, pero se tiende a preservar la voluntad. Sin embargo, dado el caso de querer revocarlo, esta declaración puede ser oral, ante el médico tratante, en la institución a la que pertenece el paciente. Es realmente incomprensible.

El Decreto reglamentario establece cómo se expresará la voluntad. Puede ser mediante un prototipo de formulario, sin actuación notarial o con actuación notarial, confundiendo términos que evidencian el desconocimiento de la actividad notarial en su conjunto.

La ley menciona que esta voluntad anticipada también se podrá otorgar ante escribano público, por escritura pública o acta notarial, y el decreto también lo recuerda, aunque no tienen muy en claro de qué trata la función notarial, ni su contenido. Dice: “deberá protocolizar el formulario o testimoniarlo, según el procedimiento seguido, sea el de la escritura pública o el del acta notarial".

Ciertamente, confunden una cosa con otra. No se hace una referencia exacta a los registros que lleva el escribano o cuáles son los fines y contenidos. En definitiva, no diferencia ni valora el documento público notarial.

\footnotetext{
11 1585. Cuando la parte no sepa o no pueda firmar, lo hará por ella uno de los testigos simultáneamente presentes al acto, los cuales no podrán ser menos de dos y deberán saber firmar. En este caso, tratándose de suma o valor de más de 100 unidades reajustables (artículo 1595) si mediare desconocimiento de la parte (artículo 1583 inciso 2º), servirá el instrumento como principio de prueba por escrito, desde que fuere reconocido por los testigos instrumentales.
} 
¿Qué se pretendió decir en el Decreto reglamentario sobre la forma notarial? Es incierto.

En Uruguay, el notario tiene a cargo dos registros: protocolo, en el cual se extienden escrituras públicas, y protocolizaciones, en las cuales se incorporan documentos y actas notariales. Los documentos derivados de estos registros son las primeras copias y los primeros testimonios de protocolización, respectivamente.

La frase transcrita es de una gran incomprensión y, por lo tanto, en un plano de estricta interpretación literal de la norma, sería imposible de implementar.

A partir de la firma de la declaración, se establece cuáles son las etapas siguientes:

- Se deberá incorporar a la historia clínica del paciente y deberá ser entregado en sobre cerrado, sin indicar quién lo debe abrir. Proceder a su incorporación (para asegurar la confidencialidad), pero a su vez deberá estar en lugar visible y fácilmente ubicable -otro desacierto-.

- En cuanto a la revocación, reitera que puede ser oral o escrita. Si es escrita, no tiene que seguir la forma de la primera declaración. Es decir, si fue ante escribano, se puede realizar por documento privado.

- Si se formaliza de manera oral, no se establece la valoración del consentimiento.

\section{Inconvenientes que presenta el instituto de la representación}

A lo anterior se suma la representación, un "sustituto de la voluntad del titular”. Necesariamente deberá estar contenida en la declaración, lo cual trae más problemas que soluciones.

Artículo 6.- En el documento de expresión de voluntad anticipada a que se alude en el artículo $2^{\circ}$ de la presente ley, se deberá incluir siempre el nombramiento de una persona denominada representante, mayor de edad, para que vele por el cumplimiento de esa voluntad, para el caso que el titular se vuelva incapaz de tomar decisiones por sí mismo. Dicho representante podrá ser sustituido por la voluntad del titular o designarse por éste sustitutos por si el representante no quiere o no puede aceptar una vez que fuera requerido para actuar. No podrán ser representantes quienes estén retribuidos como profesionales para desarrollar actividades sanitarias realizadas a cualquier título con respecto al titular. 
Este artículo es un gran nudo gordiano. ¿Qué sucede si la persona no nombra sustituto al querer que la única voluntad válida sea la suya?, ¿es nula?, ¿no debe ser tomada en cuenta?

La figura del representante resulta innecesaria ante una declaración ya formulada, donde consta una decisión tomada, previamente meditada y evaluada con todas las garantías en la información que se creyó oportuna, referente a procedimientos médicos, presentes o futuros.

Muy diferente es el caso que plantea el artículo 7, el cual también es impreciso en cuanto a si el paciente no expresó su voluntad. Establece un orden sobre quienes pueden expresarlo por él:

Artículo $7^{\circ}$. En caso que el paciente en estado terminal de una patología incurable e irreversible, certificada de acuerdo con las formalidades previstas en el artículo $5^{\circ}$ de la presente ley, no haya expresado su voluntad conforme al artículo $2^{\circ}$ de la presente ley y se encuentre incapacitado de expresarla, la suspensión de los tratamientos o procedimientos será una decisión del cónyuge o concubino o, en su defecto, de los familiares en primer grado de consanguinidad, sin perjuicio de lo dispuesto en el artículo $8^{\circ}$ de la presente ley.

Crea dificultades saber quiénes son los que pueden tomar las decisiones en el momento donde el derecho de familia y filiación está reviendo antiguas concepciones frente a modelos impuestos por la realidad, tales como el quiebre de la figura del matrimonio perpetuo, las familias ensambladas, las monoparentales, o el cumplimiento de roles por otros integrantes de la familia.

En el derecho vigente uruguayo, la figura del concubino es reconocida a texto expreso y esa unión concubinaria no disuelve el vínculo matrimonial anterior. ${ }^{12}$

Se puede dar que un enfermo terminal tenga cónyuge y concubino durante el padecimiento. La ley no distingue en este caso cuál es la decisión que debe aplicar. Tampoco indica quién sería la persona que decidiría en caso de que el paciente estuviera casado y, a su vez, viviera en concubinato.

El Decreto reglamentario realiza una serie de precisiones con respecto a la forma de probar la calidad de cónyuge o concubino, y establece para este último la exhibición de la sentencia de reconocimiento de la unión concubinaria o, en ambos casos, dos testigos. En el caso del concubino, los testigos deberán declarar que es efectivamente concubino del paciente y que lo ha sido por un lapso de cinco años.

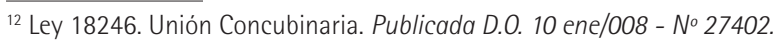


Asimismo, se genera un problema en cuanto a los familiares en primer grado, al no establecerse si son ascendientes o descendientes. De estar vivo alguno de los padres del enfermo y a su vez tener hijos mayores de edad, ¿quién deberá decidir? ¿Se requiere conformidad de todos? ¿Cuál es la certeza que puede tener el cuerpo médico en cuanto a la legitimación de quien toma la decisión? ¿Qué responsabilidad corresponde al médico?

Los plazos que se manejan son largos para sobrellevar un sufrimiento.

\section{Colofón}

El número de voluntades anticipadas otorgadas en Uruguay es muy pequeño. La mayoría se debe a la actividad notarial, a la confianza que genera en el profesional, al consejo y a la información. Sin embargo, hay poca difusión y eso depende de la actitud de los propios centros de salud, lo cual implica un incumplimiento en los derechos de los usuarios.

Para culminar de la mejor forma, queremos reivindicar que las instituciones médicas son responsables del bienestar de los usuarios de su servicios. La letra de ley no se debe convertir en letra de muerte por ineficiencia de un sistema que está condenado al fracaso al no tomar las medidas precisas para su efectiva puesta en marcha. Nada puede funcionar ante tantas incertidumbres y formas procedimentales imposibles de aplicar. La normativa actual merece una revisión mas allá de la interpretación piadosa que uno puede dar conmovido ante el sufrimiento ajeno.

Por último, culminaré este artículo con palabras que ilustran de manera certera los derechos del paciente terminal, propuestas por el especialista español en cuidados paliativos, el doctor Gómez Sancho, con motivo de su visita a Uruguay hace unos años: ${ }^{13}$

- Tengo derecho a ser tratado como un ser humano vivo hasta el momento de mi muerte.

- Tengo el derecho de mantener una esperanza, cualquiera que sea.

- Tengo el derecho de expresar a mi manera mis sentimientos y mis emociones por lo que respecta al acercamiento de mi muerte.

- Tengo el derecho de obtener la atención de médicos y enfermeras, incluso si los objetivos de curación deben ser cambiados por objetivos de confort.

\footnotetext{
${ }^{13}$ Gómez Sancho, Marcos y Ojeda Martin, Manuel. Cuidados paliativos. Control de Sintomas [En línea] 2003, p. 148. Disponible en: /libros/control_sintomas.pdf
} 
- Tengo el derecho a no morir solo.

- Tengo el derecho a ser liberado del dolor.

- Tengo el derecho de obtener una respuesta honesta, cualquiera que sea mi pregunta.

- Tengo el derecho a no ser engañado.

- Tengo el derecho de recibir ayuda de mi familia y para mi familia en la aceptación de mi muerte.

- Tengo el derecho de conservar mi individualidad y de no ser juzgado por mis decisiones, aunque pueden ser contrarias a las creencias de otros.

- Tengo el derecho de ser cuidado por personas sensibles y competentes, que van a intentar comprender mis necesidades y serán capaces de encontrar algunas satisfacciones ayudándome a enfrentarme con la muerte.

- Tengo el derecho de que mi cuerpo sea respetado después de mi muerte.

- Tengo el derecho de morir en paz y con dignidad. 